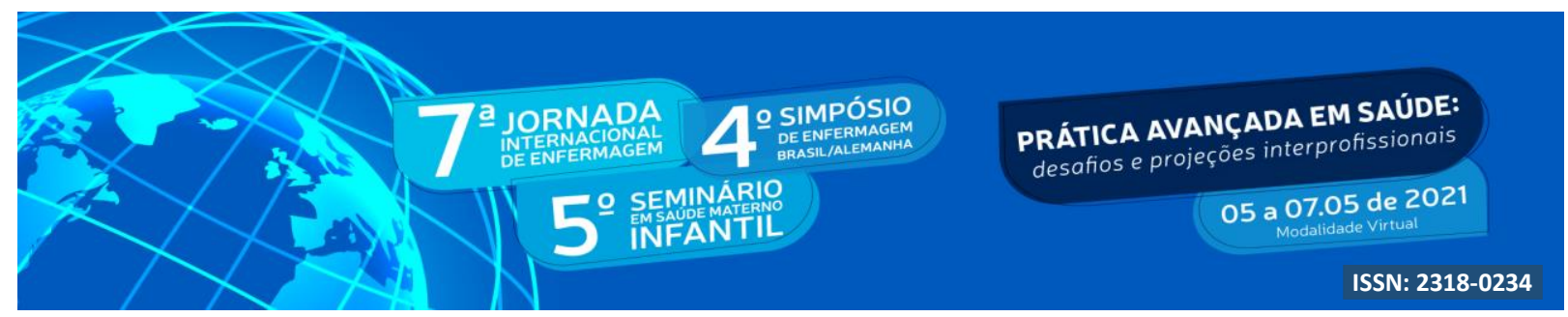

DOI: http://doi.org/10.48195/jie2021-090

\title{
COMPETÊNCIAS DO ENFERMEIRO NO GERENCIAMENTO DOS SERVIÇOS DE SAÚDE: AVANÇOS E DESAFIOS NAS INSTITUIÇÕES HOSPITALARES ${ }^{1}$
}

\author{
Ana Rita Esteves Lima²; Eduardo Marques Machado ${ }^{3}$ Liliane Alves Pereira $^{3}$
}

\begin{abstract}
RESUMO
O presente artigo tem como objetivo, analisar as competências do enfermeiro no contexto hospitalar, e a relevância de suas capacidades no que concerne o sistema gerencial frente os desafios das instituições. Para tanto, realizou-se uma revisão bibliográfica, nas bases de dados, LILACS; BDENF; MEDLINE, a partir dos descritores, Enfermeiros; Competências Profissionais; Gerenciamento, no período de 2015 a 2021. Como também utilizou-se algumas referências bibliográficas consultadas no Google acadêmico, SCIELO, livros, teses, no período de 2013 à 2019. Como resultados, foi possível perceber o quanto os realces deste estudo apontam medidas que favorecem o enfermeiro na dimensão que predominam atividades de gerenciamento. Dentre elas evidenciou-se o envolvimento e a segurança nas tomadas de decisões. Conclui-se, que este estudo seja de grande relevância ao contribuir para que enfermeiros e organizações estejam atentos quanto as competências necessárias para esclarecer saberes gerenciais, como também se identificou lacunas desse conhecimento na sua formação.
\end{abstract}

Palavras-chave: Enfermeiros; Competências Profissionais; Gerenciamento.

\begin{abstract}
This article aims to analyze the competencies of nurses in the hospital context, and the relevance of their capacities regarding the management system in the face of the challenges of institutions. To this do so, a literature review was carried out in lilacs databases; BDENF; MEDLINE, from the descriptors, Nurses; Professional Skills; Management, in the period from 2015 to 2021. As well as some bibliographic references consulted in google scholar, SCIELO, books, theses, in the period from 2013 to 2019. As results, it was possible to perceive how much the highlights of this study indicate measures that favor nurses in the dimension that predominate management activities. Among them was the involvement and security in decision-making. It is concluded that this study is of great relevance in contributing to nurses and organizations being aware of the skills necessary to clarify managerial knowledge, as well as identifying gaps in this knowledge in their education.
\end{abstract}

Key Words: Nurses; Professional Skills; Management.

\footnotetext{
${ }^{1}$ Trabalho de Pesquisa.

${ }^{2}$ Enfermeira. Estudante do Curso de Pós-Graduação em Emergências Respiratórias. Centro universitário

Internacional/ UNINTER. E-mail: anaritaesteveslima@yahoo.com.br

${ }^{3}$ Estudante de enfermagem da Universidade Franciscana-UFN

${ }^{3}$ Professora Dra. do Curso de Enfermagem - UFN. Liliane.pereira@unifra.br
} 


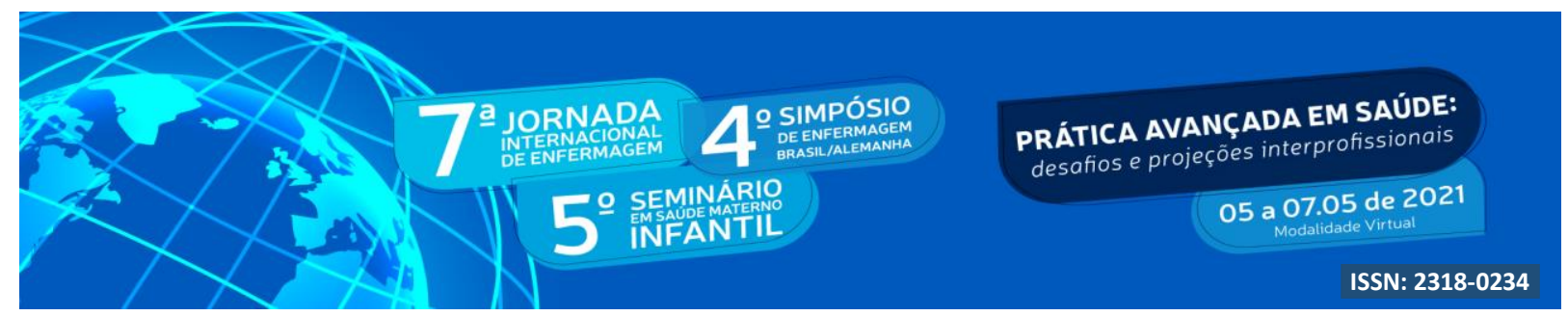

\section{INTRODUÇÃO}

No mundo contemporâneo, percebe-se que a gestão hospitalar vem se destacando cada vez mais com a presença de enfermeiros competentes e comprometidos com o sistema gerencial. Nesse sentido, a liderança é considerada uma competência relevante neste cenário para o alcance de metas organizacionais e coletivas no ambiente de trabalho. Sendo assim, a crescente complexidade dos sistemas de saúde tem sido amplamente discutida em busca desses profissionais qualificados com competências em inovação, criatividade, trabalho em equipe nas tomadas de decisões (SILVA, 2013).

Com base na observação, ao longo dos anos a gestão de qualidade, vem surgindo naturalmente nas organizações institucionais. Pensando nisso, cabe salientar que o tema competência profissional tem se constituído como foco de atenção dos enfermeiros e gestores hospitalares, pois a equipe de enfermagem representa em termos quantitativos, parcela significativa dos Recursos Humanos (RH) alocados nestas instituições. No entanto, interferem diretamente na competência e na qualidade e no custo da assistência prestada (SANTOS et al., 2016).

Nessa afirmação, Santos et al (2016), fala da importância de formar ou estimular competências profissionais e pressupõe trabalho diferenciado no interior da organização. Desse modo, conforme o autor, o enfermeiro competente deve buscar constantemente instrumentos ou estratégias para desenvolvê-las, dispondo de recursos humanos com domínio da prática, por meio da competência profissional, que permita exercer seu trabalho com eficiência.

Percebe-se que o desafio em determinar precisamente o que é qualidade gerencial no atual contexto da gestão dos serviços no campo de saúde também é influenciado por tais transformações, pois o modelo de gerenciamento original é exigido em todos os espaços de saúde: Públicas e privadas e nas parcerias entre ambas, o que acaba por pressionar os profissionais da saúde pela investigação de atualização e revisão de conceitos administrativos, uma vez que os sistemas de saúde já não são mais os mesmos, e para isto, é necessário inovar a gestão no mundo globalizado e tecnológico (ARAGÃO, 2016).

Partindo do pressuposto, a perspectiva adotada nesse sistema, mostra que o processo de trabalho do enfermeiro se dá na construção de esferas gerencial e assistencial, capazes de 


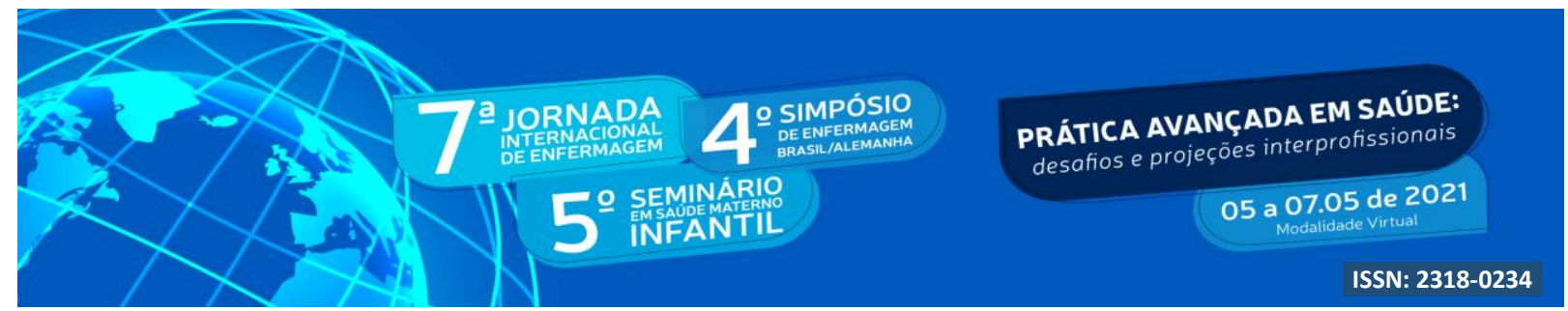

lidar com tecnologias constantemente renovadas, perpassando as experiências no ensino e na pesquisa, tornando-o, dessa forma, um gerenciador do cuidado. Isto requer competências profissionais, interação com os elementos de uma determinada condição para seu desenvolvimento, valores, habilidades e atitudes necessárias para o desempenho eficaz que alcance dos objetivos estabelecidos (BORDIN, 2018).

Nessa certeza, cabe ressaltar que essa evolução traz consigo uma visão de gestão hospitalar ampla e relevante, que pode ser compreendida como um fio condutor capaz de renovar em sua essência, a forma de planejamento e o desenvolvimento de profissionais mais comprometidos com suas responsabilidades. Nesse sentido, a incorporação de novas tecnologias exige que o profissional enfermeiro tenha na sua base a formação e o conhecimento dentro da competência gerencial e organizacional necessárias para sua atuação (FERRARI, 2014).

Considera-se, ainda, que as características organizacionais podem ser facilitadoras ou não de modelos de assistência, um fator importante observado no âmbito da gestão hospitalar são as divergências interpessoais nas organizações prestadoras de serviços de saúde. São conflitos provenientes de discordâncias que se sustentam, na disputa de interesses pessoais e profissionais, bem como em problemas de convivência e relações de poder. Os referidos conflitos podem ocorrer entre profissionais da área da saúde pelas dificuldades da não aceitação das normas dentro do sistema que visa disciplina e recomendações (FARIAS, 2017).

Frente os desafios que uma instituição possa enfrentar, a liderança emerge como o principal instrumento do processo de enfermagem, também entendido como gerenciamento do cuidado. Visto que, ela está imbuída em todas as atividades do enfermeiro, durante a organização do serviço, na relação com a equipe e a instituição, assim como na tomada de decisão, que, mesmo de forma inerente, ocupa lugar de importância no perfil do profissional. (TREVISO et al., 2017).

Partindo-se da ideia, defende-se que o cuidado de enfermagem assume dimensões ampliadas nos diferentes cenários e áreas de atuação profissional, isso implica, necessariamente, em ampliar o campo de visão pessoal e profissional. Nesta perspectiva, por oferecer subsídios interessantes como resposta a um comportamento adequado, capaz de motivar, mantendo inclusive a frequência de uma pesquisa, o profissional de saúde torna-se 


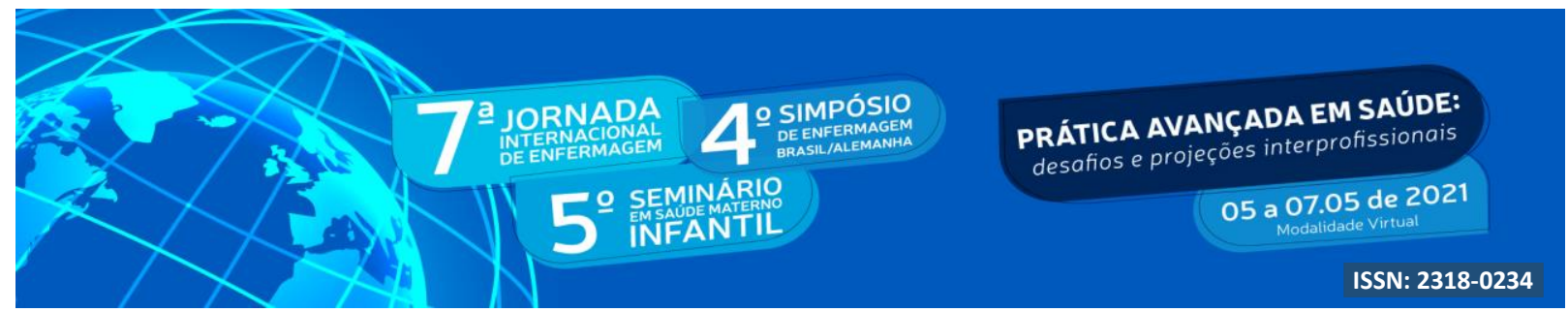

motivado e carrega consigo variadas potencialidades que, em contato com o meio adequado, desencadeiam o desejo em realizar ou empreender (BACKES et al., 2021).

Desse modo, levando em consideração os valores éticos, a competência diante dessas evoluções é de total importância para a melhoria na qualidade. Considerando que o enfermeiro, historicamente, assume cargos gerenciais nos serviços de saúde, e com destaque no âmbito hospitalar, a competência profissional para o gerenciamento é considerada essencial no papel desse trabalhador (LEAL et al., 2018).

Frente estas lacunas, Rezende et al (2013), destaca o enfermeiro na área da saúde pela multiplicidade de atividades que desenvolve, as quais incluem atividades gerenciais, administrativas e assistenciais, consideradas essenciais para um atendimento de qualidade no serviço. Frente a isso, o conhecimento e a compreensão de todos os processos ganha uma importância por incluir as competências: na Tomada de Decisão, Comunicação, Administração e Gerenciamento, Educação Permanente e Liderança, são competências a qual se dará ênfase neste trabalho.

E como destaque no âmbito das organizações prossegue com a seguinte questão. Como a gestão em saúde pode refletir de modo eficiente, na formação de enfermeiros quanto à organização da gestão hospitalar?

\section{OBJETIVO}

Analisar as competências do enfermeiro no contexto hospitalar, e a relevância de suas capacidades no que concerne o sistema gerencial, frente os desafios das instituições.

\section{METODOLOGIA}

Trata-se de uma revisão de literatura, de cunho qualitativo por meio de pesquisa bibliográfica em matérias já elaborados, buscando os objetivos propostos e o aprimoramento de ideias e conceitos de leitura recorrente em artigos científicos publicados nos bancos de dados eletrônicos, no período de 2015 a 2021. Durante as buscas foram empregados os descritores: "enfermeiros", "competências profissionais", "gerenciamento". Foram consultadas as bases de dados informatizadas no portal da (BVS) Biblioteca Virtual de Saúde: LILACS (Literatura Latino Americana e do Caribe em Ciências da Saúde); BDENF- 


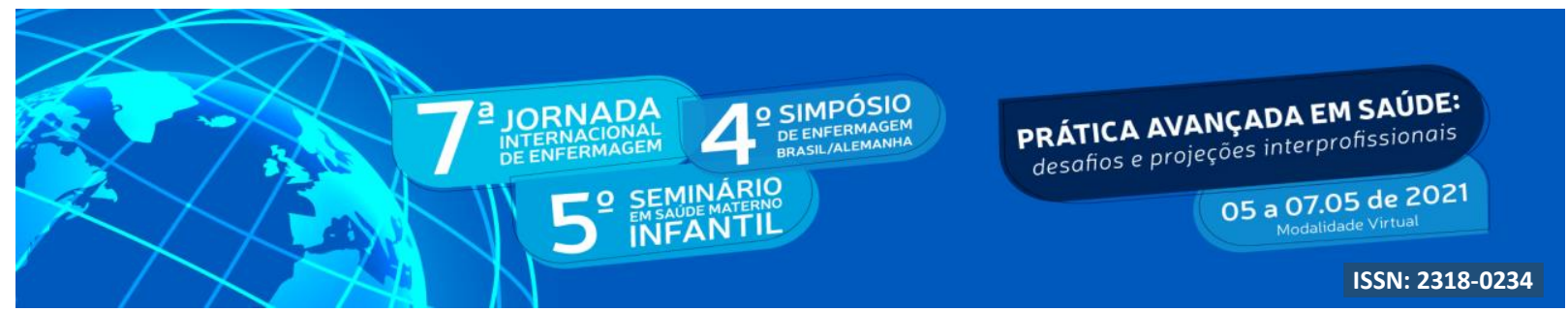

Enfermagem (Base de Dados de Enfermagem-Bireme); MEDLINE, (Medical Literature Analysis and Retrieval System Online). Como também utilizou-se algumas referências bibliográficas consultadas no Google acadêmico, SCIELO, (Scientific Electronic Library Online), livros, teses, no período de 2013 à 2021 no decorrer do artigo.

As etapas que conduziram esta revisão foram: A escolha do tema, buscas de fontes, leitura dos materias, e os resultados finais. Posteriormente foi realizada a leitura na integra dos artigos selecionados, foram retirados os materiais que não atenderam o objetivo da revisão de literatura, e os achados encontrados nesses trabalhos foram organizados e discutidos.

\section{RESULTADOS E DISCUSSÃO}

Os constantes avanços nos cenários atuais, especialmente no âmbito hospitalar, têm impressionado muito em como as gerências das instituições de saúde estão adotando métodos de avaliação dos seus serviços com base em indicadores para tomadas de decisões na busca de melhorias de seus processos e resultados. A enfermagem, como parte fundamental desse processo é de grande relevância nas instituições hospitalares, deve se instrumentalizar com ferramentas que avaliem o desempenho e a qualidade dos seus serviços para as melhorias de seus resultados (ROSSANEIS et al., 2015).

Com isso, percebe-se que os avanços científicos têm contribuído de forma efetiva no cumprimento dessas metas e da visão das instituições de saúde. Pensando nisso, as competências só podem ser possíveis quando se estabelece laços de confiança e de organização no trabalho, isto é, regra que perpassam pela assistência, para a qualidade do gerenciamento. A esse respeito, profissionais têm sido alvo de preocupações e atenção dos gestores, bem como os próprios enfermeiros que atuam na gerência e no cuidado (SOARES et al., 2019).

Neste contexto, estudos evidenciaram que ainda existe a suposição de que qualquer profissional sabe gerir e que a administração se aprende na prática. São poucos os gestores ou gerentes que possuem formação específica, com apreensão de conhecimentos e habilidades próprias da gestão, entre elas: liderar grupos, favorecer a motivação e contribuir para a eficácia e veracidade das organizações e melhoria da qualidade de vida das pessoas no 


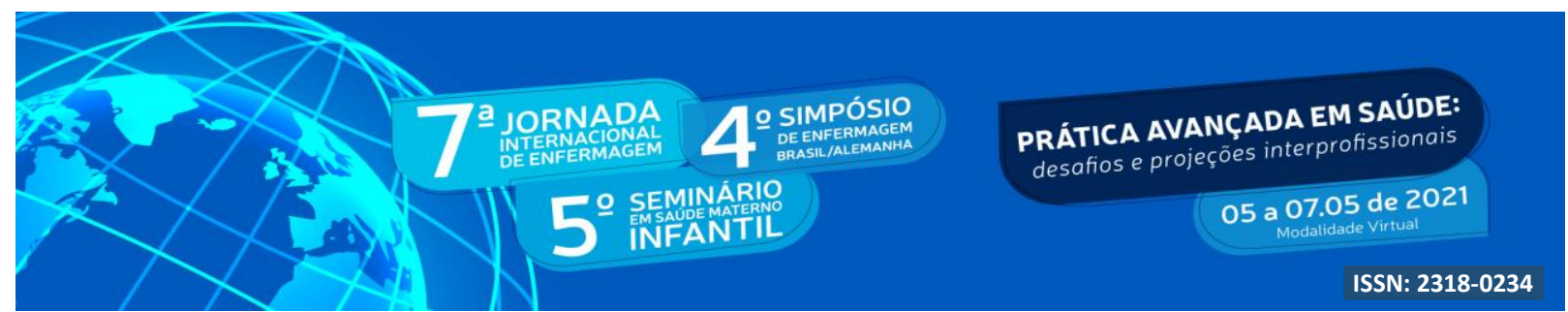

trabalho. Para estudar tais problemas, os enfermeiros vêm utilizando métodos flexíveis e dinâmicos que os possibilitam esclarecer seus objetos de estudo e alcançar os objetivos propostos em seus trabalhos. Pois a gestão de conflitos que integra o processo de trabalho gerencial dos enfermeiros, deve ser realizada de modo a evitar o rompimento do trabalho em equipe, o que limitaria ainda mais a prática de gerenciamento dos enfermeiros (LAZONI et al., 2015).

Para Nogueira (2018), a gestão em enfermagem é dotada de inúmeras tarefas e desafios para aqueles que optam por desempenhar esta função. Diariamente, situações complexas são vivenciadas em praticamente todos os ambientes onde há atividades burocráticas, administrativas, reuniões e negociações com o corpo docente, discente e diretoria. Nesse sentido, é preciso ter competência para elaboração e criação de projetos coletivos integrados nestas instituições, estabelecimentos de parcerias para tentar compreender os múltiplos fenômenos que ocorrem nesses cenários, e entender as diversas percepções e significados que os indivíduos desenvolvem sobre tais fenômenos.

Frente a isso, Silva et al (2018), em seu artigo descreve que a mudança na forma de o enfermeiro executar o trabalho, no sentido de articular o assistencial e o gerencial, poderá propiciar maior visibilidade à sua atuação. Dessa forma, o enfermeiro como gestor e profissional responsável tecnicamente pela sua equipe, deve promover e estimular o aprimoramento de seus componentes, aperfeiçoando os conhecimentos e habilidades técnicas e também as relações humanas. Entretanto, o processo de trabalho do enfermeiro está pautado no cuidar gerenciando e no gerenciar cuidando, de forma inter-relacionada. Isso inclui planejamento, tomada de decisão, resolução de problemas, liderança, comunicação, gerenciamento e conflitos de pessoas.

Com essa mesma ideia, Gaspar et al (2017), destaca-se que, nos cenários hospitalares, o enfermeiro tem competência privativa para promover o gerenciamento do cuidado de enfermagem, que envolve simultaneamente as dimensões administrativas e assistenciais do seu processo de trabalho. Assim, para atender melhor e efetivamente às necessidades do cliente, é necessário defender sua autonomia e promover qualidade de vida, para isso, esse mesmo profissional precisa de organização e planejamento, para um cuidado de qualidade.

Diante deste contexto, acredita-se que os desafios no gerenciamento hospitalar ocorrem quando há falha de processo de organização dos serviços, bem como falta de 


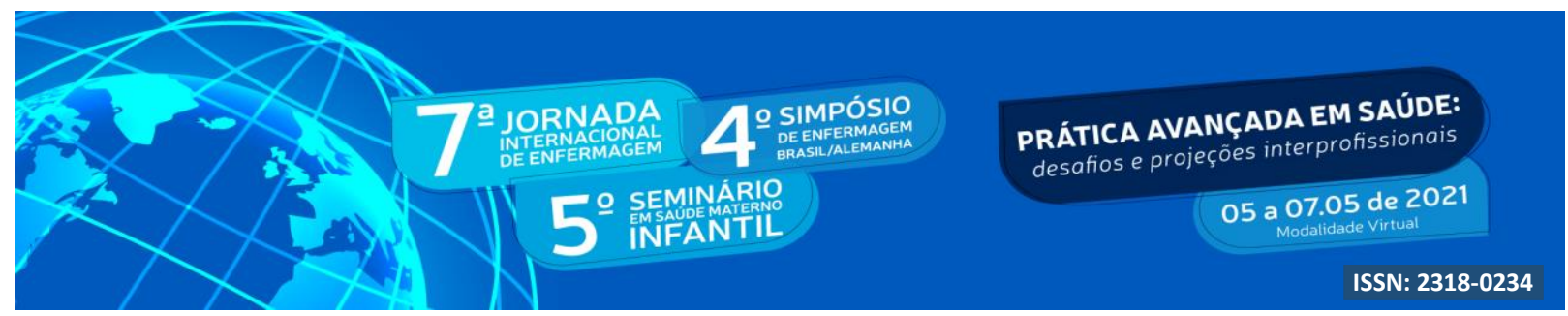

liderança ou de condutas que modifiquem essa realidade. Com esta concepção percebe-se que dentre os desafios, que emerge fomentam o comprometimento dos profissionais que dispõem de fundamentos essenciais para assistência em saúde, aumentando o padrão de qualidade, evitando eventos adversos e danos aos clientes e a instituição. Dessa forma, quando há um evento adverso, toda a estrutura organizacional sofre consequências sejam elas sociais, econômicas ou materiais ( GOMES et al., 2016).

Nesse sentido, Damasceno et al. (2016) afirma que, os indicadores de processos gerenciais mostram que na dimensão gerencial predominam atividades de gerenciamento por competências e eficiência. A articulação da dimensão gerencial e assistencial pode ser observada na referência à vista do enfermeiro os mesmos com saberes gerenciais que o faz hábil na e para a função, a saber: conhecimento, liderança, tomada de decisão, planejamento e organização, bem como a relevância do aprimoramento e a capacitação contínua desses profissionais no que diz respeito às práticas gerenciais (PEREIRA et al., 2015).

Camelo et al. (2016), corrobora com este pensamento quando descreve ser fundamental o trabalho do enfermeiro no contexto das mudanças organizacionais em especial, administrativa pautada na revisão de processos gerenciais. Assim por exemplo, competências requeridas e apresentadas pelos profissionais contribuem para melhor alocação nos postos de trabalho, facilitando a identificação de lacunas e o direcionamento de atividades. Neste sentido, este artigo, apoia-se em pressupostos teóricos que se fundamentam em concepções e visões de mundo sustentado por diversos saberes.

Por conseguinte, Rocha (2016), sugere que ao se discutir as competências do enfermeiro, inicialmente, deve ser relevante à inserção dessa temática na formação do profissional. Pois se compreende como competência, a capacidade de mobilizar e aplicar conhecimentos em uma determinada situação. Nesta ótica, para que haja competência, é necessária a ação de vários recursos como conhecimentos, capacidades cognitivas, capacidades integrativas, capacidades relacionais, dentre outros, os quais são testados frente aos desafios de um novo projeto e organização.

Portanto, os enfermeiros gestores devem se preocupar em analisar o desempenho dos profissionais por meio de instrumentos que avaliem as suas competências trabalhadoras. Para isso é preciso manter um bom equilíbrio e comportamento assertivo, saber identificar o contexto e o cenário que está inserido, visto que suas ações precisam saber quando promover 


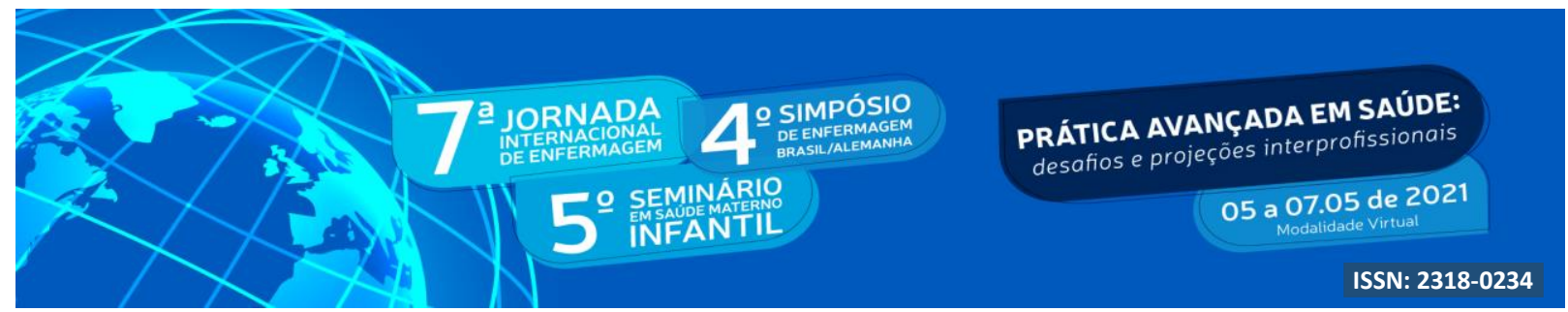

a defesa e quando há risco de ser mal interpretado por outros profissionais da instituição onde desempenha sua função (SOARES et al., 2019).

\section{CONCLUSÃO}

Conclui-se, que os artigos descritos nos resultados focaram significativamente nas competências dos processos gerencias do enfermeiro e nos desafios que se enfrentam para desempenhar esta função. Entretanto, cabe a o enfermeiro o incentivo e reflexão da quão importante é a sua participação nos processos gerenciais e administrativo de uma instituição.

Acredita-se, que este estudo contribui para que os enfermeiros e as organizações estejam atentos quanto as competências necessárias aos saberes gerenciais, como também identificou-se lacunas desse conhecimento na sua formação. Para isso os gestores de instituições hospitalares em especial o enfermeiro, estão imbuídos pelo desejo de fazer com êxito a gestão de forma concreta e com qualidade.

Por fim, fica a intenção de que este trabalho seja incentivo para os profissionais enfermeiros que têm a missão de organizar, administrarem, e gerenciar, no intuito de aprimorar ainda mais a busca pelo bem-estar de seus profissionais numa instituição. E, para isso, destaca-se a necessidade de aprofundamento sobre o assunto referido, como fator interferente na qualidade do profissional.

\section{REFERÊNCIAS}

ARAGÃO, O. C.; TEÓFILO, J. K. S.; MOURÃO NETTOI, J. J.; SOARES, J. S. A.; GOYANNA, N. F.; CAVAlCANTE, A. E. S. Competências do enfermeiro na gestão hospitalar. Espaço para Saúde, [S. l.], v. 17, n. 2, p. 66-74, 2016. DOI: 10.22421/15177130-2016v17n2p66. Disponível em: http://espacoparasaude.fpp.edu.br/index.php/espacosaude/article/view/286. Acesso em: 14 abr. 2021.

BACKES, Dirce Stein et al. O cuidado empreendedor de enfermagem induzindo práticas saudáveis em comunidades vulneráveis. Rev. Gaúcha Enferm., Porto Alegre , v. 42, n. spe, e20200010, $2021 \quad$ Available from <http://www.scielo.br/scielo.php?script=sci_arttext\&pid=S198314472021000200403\&lng=en\&nrm=iso > access on 14 Apr. 2021. Epub Feb 03, 2021. https://doi.org/10.1590/1983-1447.2021.20200010.

BORDIN V, A.M.L; ZILLY A; JUSTINO E.T, SILVA N.D.V, FALLER J.W. Liderança em enfermagem na perspectiva de enfermeiros assistenciais de um hospital público da tríplice fronteira. Rev. Adm. Saúde - Vol. 18, No 71, abr. - jun. 2018. http://dx.doi.org/10.23973/ras.71.107. 


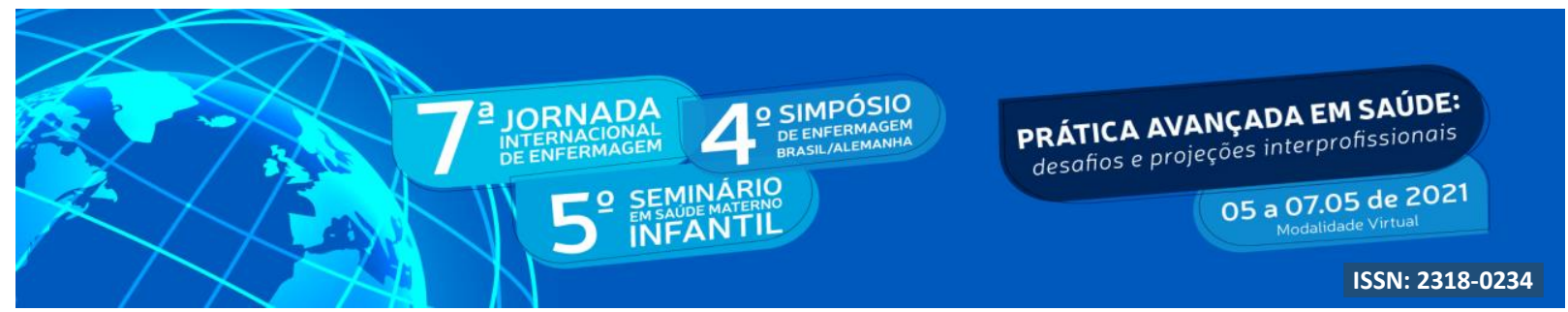

CAMELO, Henriques Silvia Helena et al . Competências profissionais e estratégias organizacionais de gerentes de enfermagem. Cienc. enferm., Concepción , v. 22, n. 1, p. 7586, abr. 2016 . Disponible en <https://scielo.conicyt.cl/scielo.php?script=sci_arttext\&pid=S0717$95532016000100007 \& \operatorname{lng}=$ es\&nrm=iso $>$.

en 12 enero 2021. http://dx.doi.org/10.4067/S0717-95532016000100007.

DAMASCENO, Carolinne Kilcia Carvalho Sena et al. O trabalho gerencial da enfermagem: conhecimento de profissionais enfermeiros sobre suas competências gerenciais. Revista de Enfermagem UFPE on line, [S.1.], v. 10, n. 4, p. 1216-1222, mar. 2016. ISSN 1981-8963. Disponível em: 〈https://periodicos.ufpe.br/revistas/revistaenfermagem/article/view/11106/12573 >. Acesso em: 15 fev. 2021. doi:https://doi.org/10.5205/1981-8963-v10i4a11106p1216-1222-2016.

FARIAS, Diego Carlos; ARAUJO, Fernando Oliveira de. Gestão hospitalar no Brasil: revisão da literatura visando ao aprimoramento das práticas administrativas em hospitais. Ciênc. saúde coletiva, Rio de Janeiro , v. 22, n. 6, p. 1895-1904, June 2017 . Available from $<$ http://www.scielo.br/scielo.php?script=sci_arttext\&pid=S1413-

81232017002601895\&lng=en\&nrm=iso>. access on 14 Jan. 2021. http://dx.doi.org/10.1590/1413$\underline{81232017226.26432016 .}$.

FERRARI, Maria Dolores. Qualidade de vida no ambiente de trabalho: UTFPR - Curitiba e o desenvolvimento de pessoas. 2014. 165 f. Dissertação (Mestrado em Tecnologia) - Universidade Tecnológica Federal do Paraná, Curitiba, 2014.

GASPAR, Rafael Barroso et al . Fatores condicionantes à defesa da autonomia do idoso em terminalidade da vida pelo enfermeiro. Rev. Bras. Enferm., Brasília , v. 73, supl. 3, $2020 \quad$. $20180857, \quad$ Available from <http://www.scielo.br/scielo.php?script=sci_arttext\&pid=S0034-

71672020001500158\&lng=en\&nrm=iso>. access on 14 Apr. 2021. Epub July 13, 2020. https://doi.org/10.1590/0034-7167-2018-0857.

GOMES, Cátia Denise Perez Pereira et al. Percepção de uma equipe de enfermagem sobre a utilização do checklist cirúrgico*. Revista SOBECC, São Paulo, v. 21, n. 3, p. 140-145, dez. 2016. ISSN 23582871. Disponível em: 〈https://revista.sobecc.org.br/sobecc/article/view/180>. Acesso em: 20 jan. 2021. doi:https://doi.org/10.5327/Z1414-4425201600030004.

LANZONI, Gabriela Marcellino de Melo et al. Tornando-se gerente de enfermagem na imbricada e complexa fronteira das dimensões assistencial e gerencial. Revista Eletrônica de Enfermagem, [S. l.], v. 17, n. 2, p. 322-32, 2015. DOI: 10.5216/ree.v17i2.29570. Disponível em: https://revistas.ufg.br/fen/article/view/29570. Acesso em: 16 fev. 2021.

LEAL, Laura Andrian et al . Clinical and management skills for hospital nurses: perspective of nursing university students. Rev. Bras. Enferm., , v. 71, supl. 4, p. 1514-1521, 2018 . Disponível em $<$ http://www.revenf.bvs.br/scielo.php?script=sci_arttext\&pid=S003471672018000701514\&lng=pt\&nrm=iso > acessos em 14 abr. 2021. http://dx.doi.org/10.1590/00347167-2017-0452.

NOGUEIRA, V.O; CUNHA, I.C.K.O. Validação de conteúdo do perfil de competências de enfermeiros gestores de ensino superior. Rev Cuid, Bucaramanga , v. 9, n. 1, p. 19982006, Apr. 2018 . Available from 


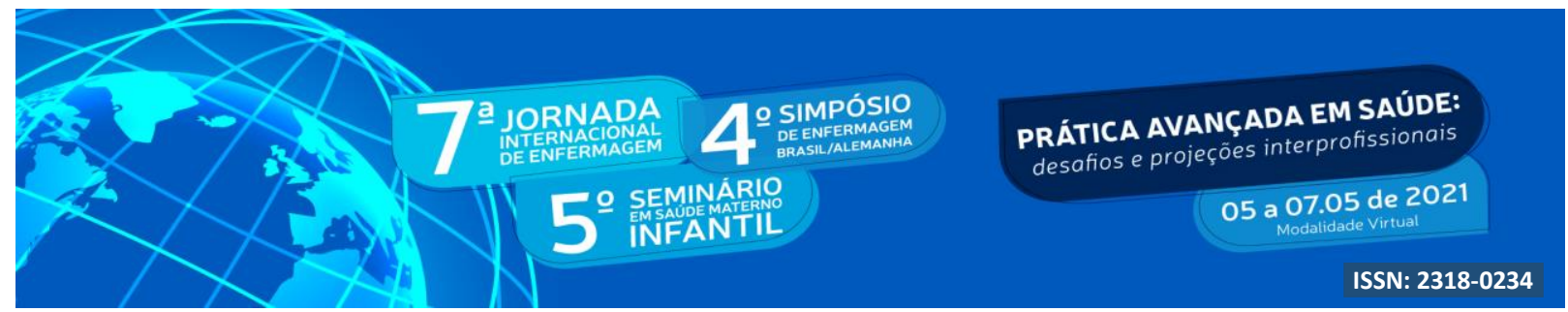

$<$ http://www.scielo.org.co/scielo.php?script=sci_arttext\&pid=S2216-

09732018000101998\&lng=en\&nrm=iso>.

access

on 17 Jan. 2021. http://dx.doi.org/10.15649/cuidarte.v9i1.474.

PEREIRA, Liliane Alves et al. Enfermagem e liderança: percepções de enfermeiras gestoras de um hospital do sul do Brasil. Revista Pesquisa Care é Fundamental Online , v. 7, n. 1 p. 1875-1882, 2015.

REZENDE, Barbara Carneiro et al. Dificuldades enfrentadas pelos enfermeiros na prática da liderança em enfermagem: uma revisão da literatura. Revista Eletrônica Gestão \& Saúde Vol.04, No .02 , Ano 2013 p.401-16.

ROCHA, Raí Moreira. Competências profissionais do enfermeiro no gerenciamento dos eventos adversos UTI neonatal. 2016. 142 f. Dissertação (Mestrado Ciências do Cuidado em Saúde) - Escola de Enfermagem Aurora de Afonso Costa, Niterói, 2016.

ROSSANEIS, Mariana Angela et al. indicadores de qualidade da assistência: opinião de enfermeiros gerentes de hospitais de ensino. Cogitare Enfermagem, [S.1.], v. 20, n. 4, dec. 2015. ISSN 21769133. Disponível em: <https://revistas.ufpr.br/cogitare/article/view/41734>. Acesso em: 16 jan. 2021. doi:http://dx.doi.org/10.5380/ce.v20i4.41734.

SANTOS, Ana Paula Azevedo et al . O enfermeiro no pós-operatório de cirurgia cardíaca: competências profissionais e estratégias da organização. Rev. esc. enferm. USP, São Paulo, v. 50, n. 3, p. 474-481, June 2016 Available from $<$ http://www.scielo.br/scielo.php?script=sci_arttext\&pid=S0080-

62342016000300474\&lng=en\&nrm=iso >. access on 16 Jan. 2021. http://dx.doi.org/10.1590/S0080$\underline{623420160000400014 .}$

SILVA, M.R; CHINI, L.T; SILVA, T.O; MARTINEZ, M.R; SANCHES, R.S. Competências dos profissionais técnicos de enfermagem: o que esperam os enfermeiros gestores?. Enfermagem em Foco, [S.1.], v. 9, n. 4, fev. 2019. ISSN 2357-707X. Disponível em: <http://revista.cofen.gov.br/index.php/enfermagem/article/view/1335/482>. Acesso em: 16 abr. 2021. doi:https://doi.org/10.21675/2357-707X.2018.v9.n4.1335.

SILVA, Vânea Lucia dos Santos; CAMELO, Silvia Helena Henriques. A competência da liderança em enfermagem: conceitos, atributos essenciais e o papel do enfermeiro líder [Nursing leadership competence: concepts, essencial attributes and the role of the nurse leader]. Revista Enfermagem UERJ, [S.1.], v. 21, n. 4, p. 533-539, mar. 2014. ISSN 0104-3552. Disponível em: <https://www.epublicacoes.uerj.br/index.php/enfermagemuerj/article/view/10031>. Acesso em: 16 jan. 2021.

SOARES, Mirelle Inácio et al . Avaliação de desempenho por competências em enfermeiros hospitalares. Rev. Latino-Am. Enfermagem, Ribeirão Preto , v. 27, e3184, 2019 . Disponível em <http://www.scielo.br/scielo.php?script=sci_arttext\&pid=S0104$11692019000100373 \& \operatorname{lng}=$ pt\&nrm=iso>. acessos em 30 jan. 2021. Epub 14-Out2019. http://dx.doi.org/10.1590/1518-8345.3173.3184.

TREVISO, Patricia et al. Competências do enfermeiro na gestão do cuidado. Rev. Adm. Saúde, v.17, n.69 (2017) [acesso em 20 jan2021]; 17(69). Disponível em: < http://www.cqh.org.br/ojs2.4.8/index.php/ras/article/view/59/77>. doi: http://dx.doi.org/10.23973/ras.69.59. 